\section{Floral Development and Breeding System of Swainsona formosa (Leguminosae)}

\author{
Manfred Jusaitis \\ Black Hill Flora Centre, Botanic Gardens of Adelaide, Maryvale Road, \\ Athelstone, South Australia, 5076
}

Additional index words. Sturt's desert pea, Clianthus formosus, stigma, pollen germination, pollination

\begin{abstract}
Flowers of Swainsona formosa (G. Don) J. Thompson (syn. Clianthus formosus) developed through seven floral stages from buds to open flowers in $\mathbf{1 7}$ days. Floral stages were correlated with the sigmoidal growth pattern of the peduncle. Self-pollination was prevented in the species by the presence of a stigmatic cuticle that precluded pollen germination until ruptured, exposing the receptive surface below. Cuticular rupture occurred in nature during bird-pollination and was emulated manually by lightly rubbing a pollen-covered finger across the stigma. The species was self-compatible, and to ensure cross-fertilization when breeding, emasculation before anther dehiscence was essential.
\end{abstract}

Strut's desert pea (Swainsona formosa), a legume native to Australia, is arguably one of the world's most striking and spectacular flowering plants. Its horticultural potential as a cut flower or as a container-grown ornamental is enormous (Barth, 1990). However, growth habit, floral characteristics, and disease resistance are extremely variable, and ample scope exists for plant improvement. This study was aimed at understanding the critical stages of floral development in relation to the breeding system of the plant as the first step in a breeding program to develop new commercial cultivars.

Swainsona formosa, a member of the subfamily Papilionoideae, has a large (up to 100mm-long) flag-shaped flower consisting of an upper standard petal (or flag) that incorporates a shiny black boss, and a lower keel that houses the sexual organs (Fig. 1). The flowers are characteristically bright red and are borne in umbels of up to six flowers subtended by a long (up to 200-mm) peduncle. Flowers are omithophilous in the wild (Armstrong, 1979). Visiting birds probing the flower through the beak-guide in the center of the boss are rewarded with copious nectar at the base of the filament sheath.

\section{Materials and Methods}

Swainsona formosa plants were routinely grown in a glasshouse maintained at $25 / 18 \mathrm{C}$ $( \pm 4 C)$ under natural daylength. Seeds (collected from Andamooka Station, South Austra-

Received for publication 4 May 1993. Accepted for publication 7 Aug. 1993. I thank C. Schmerl and K. Holliday for technical assistance and M. Sedgley for helpful discussions. I also gratefully acknowledge the Univ. of Adelaide and M. Sedgley for allowing use of the SEM, and S. McClure for its operation. This study was funded by the Rural Industries Research and Development Corp. The cost of publishing this paper was defrayed in part by the payment of page charges. Under postal regulations, this paper therefore must be hereby marked advertisement solely to indicate this fact. tically; $\mathrm{E}=$ the flag began to reflex back from the keel; $F=$ the flag in half-reflexed position was horizontal; $\mathrm{G}=$ the flag had fully reflexed and the flower was open. Flowers at each developmental stage were harvested and dissected to relate the development of internal parts to that of the whole flower.

\section{Results and Discussion}

Because of the difficulty of finding flowers developing in synchrony, floral stage and peduncle length for asynchronous flowers were plotted such that onset of stage $G$ for each flower coincided. This enabled means of synchronized floral stages (mean of five flowers) and peduncle lengths (mean of 12 flowers) to be graphed. Peduncle length followed a sigmoidal growth pattern over the period of floral development, with maximal length being attained by 19 to 20 days (Fig. 2). Flowers remained at stage A during the first half of this period, but when peduncle growth became linear (day 9), floral development accelerated quickly through stages B and C to reach stage D by day 13.2. Floral development slowed at stage D, while the peduncle continued to elongate. Flowers then accelerated through stages E-G as peduncle elongation rate declined. Floral stages $\mathrm{E}$ and $\mathrm{F}$ were the most ephemeral, together occurring within the space of a day. Floral development was therefore completed 17 days after the emergence of a floral bud, while peduncle growth continued slightly beyond that time.

Anther dehiscence commenced at floral stage $\mathrm{E}$ and was completed by stage $\mathrm{F}$. Thus, emasculation of flowers in breeding experiments should be performed during stage D, when anthers were fully developed but had not dehisced. Nectar production at the base of the filament tube commenced during stage $\mathrm{F}$, and by stage $\mathrm{G}$, each flower contained $80-100 \mu \mathrm{l}$ of nectar. Following anther dehiscence, pollen fell to the bottom of the keel and accumulated immediately posterior to the stigma in the region of stylar brush hairs. These anteriorfacing hairs play an important role in pollen extrusion from the keel during bird pollination (Arroyo, 1981), and also restrict self-pollen access to the stigma. Nevertheless, self-pollen was occasionally found in contact with the

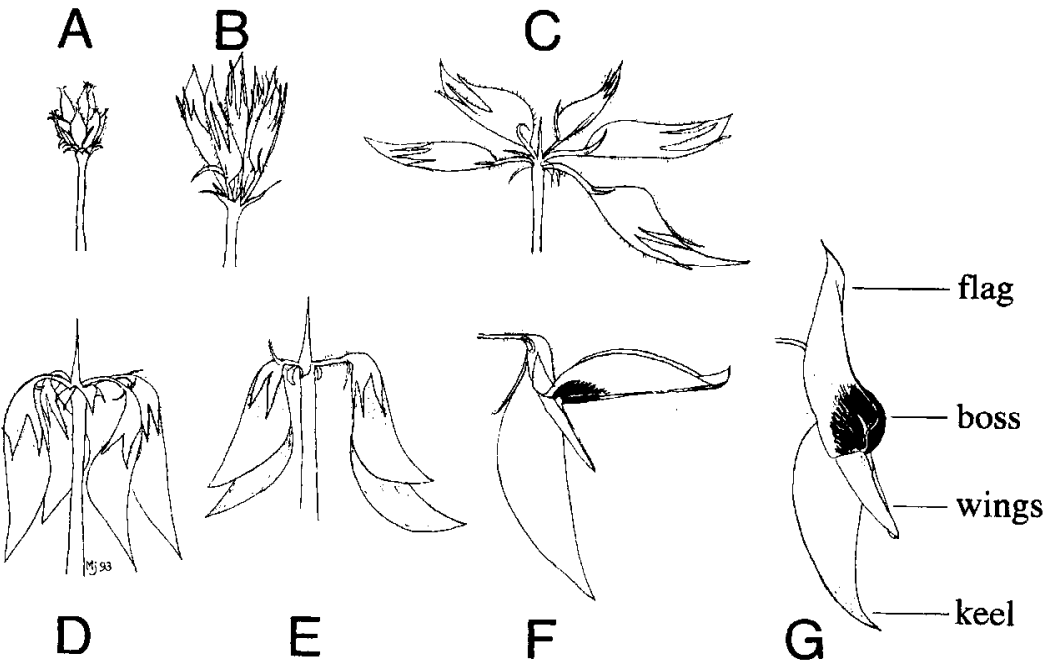

Fig. 1. Stages of floral development of Swainsona formosa. See text for description of each stage. 


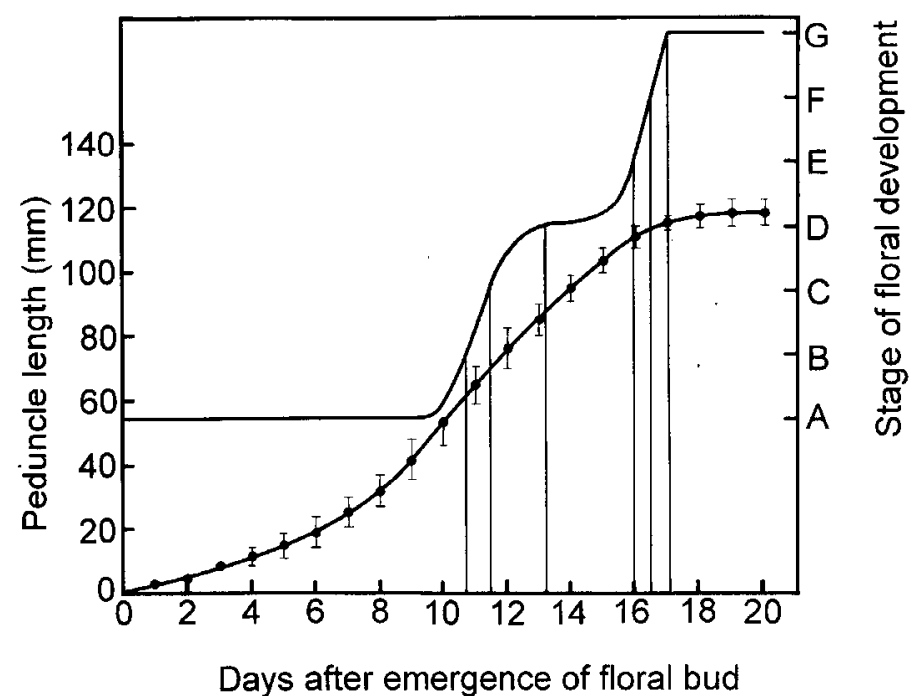

Fig. 2. Floral development patterns (upper curve) and peduncle growth (lower curve) for Swainsona formosa. Vertical lines indicate the onset of successive floral stages (see Fig. 1). Vertical bars represent \pm SE.

stigma, and the important question of how self-pollination and fertilization were prevented within a flower required investigation.

Many papilionoid legumes reportedly possess astigmatic cuticle (membrane) covering the stigma, requiring rupture before pollen will germinate (Shivanna and Owens, 1989). Such rupture can be achieved by tripping the flower, subjecting the cuticle to mechanical disturbance, or even increasing fluid pressure in the style (Lord and Heslop-Harrison, 1984). To investigate self-incompatibility and the possibility of a similar cuticular barrier to self-pollination in $S$. formosa, cross- or self-pollen was applied to stigmas of stage $\mathrm{G}$ flowers by either gently touching the stigma to a pollen mass, ensuring minimal disturbance to the stigma, or by rubbing the stigmatize times with a fingertip covered in pollen. The latter treatment was designed to simulate contact of the stigma with the abdominal surface of a pollinating bird feeding on nectar. Flowers treated with crosspollen, and control flowers that received a rub but no pollen, were all emasculated at stage D. Successful fertilizations were assessed by counting the number of pods that had set after 7 days. All set pods contained developing seed.

Rub treatments (in the presence of pollen) resulted in all flowers setting pods, regardless of whether self-or cross-pollen was used (Table 1 ), suggesting that $S$. formosa was a selfcompatible species and augmenting the list of self-compatible Swainsona sp. reported by Arroyo ( 198 1). Pod set was markedly reduced if stigmas were touched to pollen without any mechanical disturbance to the stigma tip. Pairwise $x^{2}$ tests showed no significant difference between self- and cross-pollination for touched stigmas $\left(x_{\text {ldf }}^{2}=0.25\right)$. However, touched stigmas produced significantly less pods than rubbed stigmas (all comparisons significant at $P \leq 0.001$ ). When stigmas were rubbed in the absence of pollen, no fruit were set. This evidence demonstrated that mechanical disturbance to the stigma tip was necessary to achieve fruit set.

To determine whether this barrier to fertilization was astigmatic cuticle, as proposed for
Table 1. The proportion of flowers to set pods following either astigmatic rub in the presence or absence of pollen, or the touch of an undisturbed stigma to pollen.

\begin{tabular}{lcc}
\hline $\begin{array}{l}\text { Stigmatic } \\
\text { treatment }\end{array}$ & $\begin{array}{c}\text { No. flowers } \\
\text { treated }\end{array}$ & Pod set $(\%)$ \\
\hline Rub, self-pollen & 78 & 100 \\
$\quad$ cross-pollen & 58 & 100 \\
Touch, self-pollen & 63 & 22 \\
$\quad$ cross-pollen & 54 & 18 \\
Rub, no pollen & 26 & 0 \\
$\chi^{2}$ & & $* * *$ \\
\hline$* *$ Significant at $P \leq 0.001$. &
\end{tabular}

other papilionoid legumes (Shivanna and Owens, 1989), the structure of the stigma was studied using an Electroscan ES-2 environmental scanning electron microscope. This microscope allowed fresh tissue to be observed directly without prior fixation or coating. Undisturbed stigmas had a papillate surface structure with no obvious exudate (Fig. 3A). A rubbed stigma showed the presence of a cuticle that, if rolled back, revealed the underlying stigmatic surface (Fig. 3B). Copious exudate was evident below the cuticle (Fig. 3C). Manipulation under a dissecting microscope demonstrated that this cuticle was easily dislodged by gently prodding or rubbing with the point of a needle, releasing the exudate held below. Staining freehand sections of fresh tissue with Sudan III and IV in $70 \%$ ethanol (O'Brien and McCully, 1981) resulted in orange coloration of the cuticle, revealing the presence of ethanol-soluble lipids. Cuticle thickness was estimated (using SEM and light microscopy) at between 10 and $12.5 \mu \mathrm{m}$ (see Fig. 3C), which was 25 to 100 times thicker than stigmatic cuticles of the insect-pollinated Vicia faba L. (Lord and Heslop-Hamison, 1984) or Medicago sativa L. (Kreitner and Sorensen, 1984). A thicker cuticle further reduces the risk of self-pollination through accidental rupture and is decidedly advantageous for a bird-pollinated species.

To determine whether rupture of the stigmatic cuticle was required for pollen to germinate, style tips ( 2 to $3 \mathrm{~mm}$ long) were excised from stage $\mathrm{G}$ flowers and incubated upright with their cut bases inserted into 1.5\% agar in petri dishes. Before incubation, stigmas were either rubbed five times on the surface of a petri dish containing cross-pollen (to rupture the cuticle), or pressed lightly against pollen to enable pollen to adhere with minimal disturbance to the stigmatic cuticle, or pollen was applied to completely undisturbed stigmas using the point of a needle but without touching the stigma. After $2 \mathrm{~h}$ of incubation at room temperature $(24 \pm 1 \mathrm{C})$, a subsample of pollen was removed from stigmas using the point of a needle, mounted in a drop of water on a microscope slide, and covered with a coverslip. Pollen tubes were counted under $\times 100$ magnification to determine percent germination. Viability of the pollen used in this experiment was tested on a modified Brewbaker and Kwack (1963) medium $\left[\left(\mathrm{mg}^{\bullet}\right.\right.$ liter $\left.^{-1}\right) 720 \mathrm{Ca}\left(\mathrm{NO}_{3}\right)_{2} \bullet$ $\left.4 \mathrm{H}_{2} \mathrm{O}, 200 \mathrm{MgSO}_{4} \cdot 7 \mathrm{H}_{2} \mathrm{O}, 200 \mathrm{KNO}_{3}, 20 \mathrm{H}_{3} \mathrm{BO}_{3}\right]$ with $10 \%$ sucrose and $1 \%$ agar (B\&Kmedium). Pollen was spread evenly on the surface of this medium prepared on a microscope slide and germination was assessed after $2 \mathrm{~h}$ at room temperature, as before. These treatments were replicated three times.

Pollen germination was rapid, with the first pollen tubes becoming evident after $30 \mathrm{~min}$ of incubation on B\&K medium. Nearly two-thirds of the pollen had germinated at $2 \mathrm{~h}$ (Table 2), which compares favorably with earlier estimates (Hughes et al., 1991). Nearly half of the pollen applied to a rubbed stigma germinated, while pressed stigmas supported $\approx 19 \%$ germination. The fact that germination was negligible on undisturbed stigmas (Table 2) suggests that cuticle disruption to expose the stigmatic surface, or at least cuticle bruising to release stigmatic exudate, was necessary for pollen germination to occur. The application of sizeable masses of pollen to stigmas in this experiment necessarily meant that some pollen on the outside of the mass may not have been in direct contact with the stigma or its secretions, possibly explaining the lower germination observed on rubbed stigmas compared with that on $\mathrm{B} \& \mathrm{~K}$ medium. Furthermore, penetration of some pollen tubes into the stigmatic surface during the $2 \mathrm{~h}$ of incubation may have restricted the availability of these grains for subsampling, thus further underestimating actual germination. Both the inability of pollen to germinate on the undisturbed surface of the stigma and the apparent thickness and lipoidal nature of the covering sheath suggested that this covering was a cuticle rather than a proteinaceous pellicle, as found on stigmas of Glycine max (L.) Merr. (Tilton et al., 1984) or various members of the Cruciferae and other families (HeslopHarrison et al., 1975).

During the course of this study, New Holland honeyeaters (Phylidonyris novaehollandiae Latham) were observed feeding on nectar from $S$. formosa flowers growing in open glasshouses. Birds characteristically perched on stems adjacent to flower peduncles and, in the process of feeding, the style was thrust from the keel to deposit pollen sternotribically onto the bird's abdomen. While the bird probed the nectary, the stigma came in contact with 

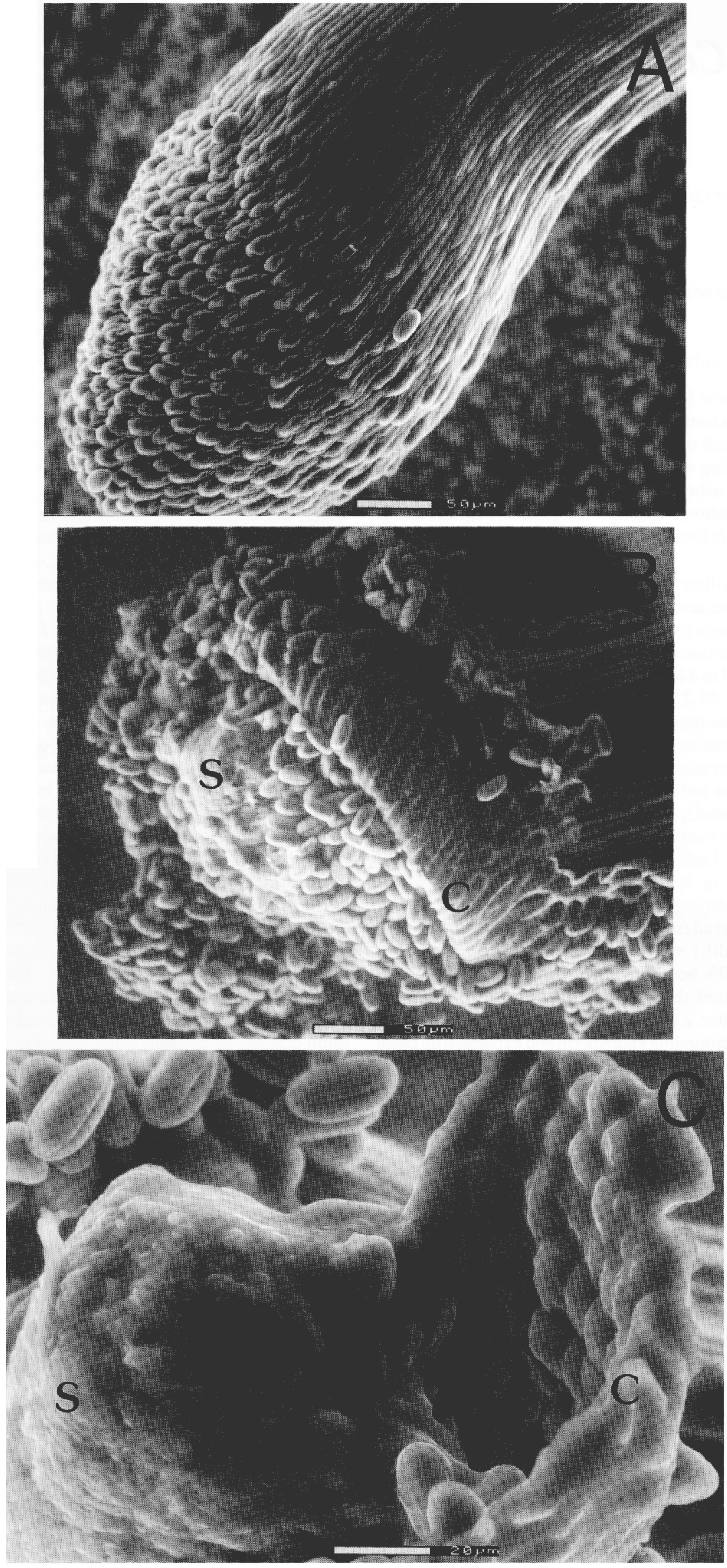

Fig. 3. Scanning electron micrographs of Swainsona formosa stigmas at floral stage G. (A) Undisturbed stigma showing cuticle surface structure. (B) Rubbed and pollinated stigma showing the peeled-back cuticle (c) and exposed stigmatic surface (s). (C) Rubbed stigma showing thick cuticle (c) and underlying stigma (s).
Table 2. In vitro germination of Swainsona formosa pollen on excised styles following various stigmatic treatments, or on B\&K pollen germination medium, after $2 \mathrm{~h}$ of incubation.

\begin{tabular}{lc}
\hline Treatment & Germination (\%) \\
\hline Stigma rub & 43.3 \\
Stigma press & 19.4 \\
Untreated stigma & 1.3 \\
B\&K medium & 64.7 \\
LSD $(P \leq 0.05)$ & 5 \\
\hline
\end{tabular}

and was rubbed against the bird's abdominal feathers, demonstrating how the process of stigmatic cuticle rupture and subsequent pollination could occur in nature. When the beak was withdrawn from the flower, the style retracted back into the keel.

A similar cuticular system for encouraging cross-pollination has been observed in another ornithophilous legume, Lotus berthelotii Masferrer (Owens, 1985). However, to the best of our knowledge, this report is the first to describe this phenomenon in a member of the tribe Galegeae; it also established that $S$. formosa is a self-compatible species that needs to be emasculated during floral stage $\mathrm{D}$ to ensure effective crossing in a breeding program. Furthermore, mechanical disruption of the stigmatic cuticle was essential for successful crossing or selfing to occur. This was achieved easily by lightly rubbing the stigma with a fingertip covered in pollen.

\section{Literature Cited}

Armstrong, J.A. 1979. Biotic pollination mechanisms in the Australian flora-A review. New Zealand J. Bet. 17:467-508.

Arroyo, M.T.K. 1981. Breeding systems and pollination biology in Leguminosae, p. 723-769. In: R.M. Polhill and P.H. Raven (eds.). Advances in legume systematic. Royal Bet. Garden, Kew.

Barth, G.E. 1990. Cut flower potential of Sturt's desert pea. Austral. Hort. 88(8):48-53.

Brewbaker, J.L. and B.H. Kwack. 1963. The essential role of calcium ion in pollen germination and pollen tube growth. Amer. J. Bet. 50859-865.

Heslop-Harrison, J., Y. Heslop-Harrison, and J. Barber. 1975. The stigma surface in incompatibility responses. Proc. Royal Soc London, Ser. B. 188:287-297.

Hughes, H.G., C.W. Lee, and L.E. Towill. 1991. Low-temperature preservation of Clianthus formosus pollen. HortScience 26:1411-1412.

Kreitner, G.L. and E.L. Sorensen. 1984. Stigma development and the stigmatic cuticle of alfalfa, Medicago sativa L. Bet. Gaz. 145:436-443.

Lord, E.M. and Y. Heslop-Harrison. 1984. PollenStigma interaction in the Leguminosae: Stigma organization and the breeding system in Vicia faba L. Ann. Bet. 54827-836.

O'Brien, T.P. and M.E. McCully. 1981. The study of plant structure. Principles and selected methods. Termarcarphi Pty., Melbourne, Australia.

Owens, S.J. 1985. Seed set in Lotus berthelotii Masferrer. Ann. Bet. 55:811-814.

Shivanna, K.R. and S.J. Owens. 1989. Pollen-pistil interactions (Papilionoideae). In: C.H. Stirton and J.L. Zarucchi (eds.). Advances in legume biology. Monogr. Syst. Bet. Missouri Bet. Garden 29: 157-182.

Tilton, V.R., L.W. Wilcox, R.G. Palmer, and M.C. Albertsen. 1984. Stigma, style and obturator of soybean, Glycine max (L.) Merr. (Leguminosae) and their function in the reproductive process. Amer. J. Bet. 71:676-686. 